\title{
A Pole Pair Segment of a 2-MW High-Temperature Superconducting Wind Turbine Generator
}

Song, Xiaowei (Andy); Mijatovic, Nenad; Kellers, Jürgen; Bührer, Carsten; Rebsdorf, Anders V.; Hansen, Jesper; Christensen, Mogens; Krause, Jens; Pütz, Hendrik; Wiezoreck, Jan

Total number of authors:

11

Published in:

IEEE Transactions on Applied Superconductivity

Link to article, DOI:

10.1109/TASC.2017.2656778

Publication date:

2017

Document Version

Peer reviewed version

Link back to DTU Orbit

Citation (APA):

Song, X., Mijatovic, N., Kellers, J., Bührer, C., Rebsdorf, A. V., Hansen, J., Christensen, M., Krause, J., Pütz, H., Wiezoreck, J., \& Holbøll, J. (2017). A Pole Pair Segment of a 2-MW High-Temperature Superconducting Wind Turbine Generator. IEEE Transactions on Applied Superconductivity, 27(4), [5201205].

https://doi.org/10.1109/TASC.2017.2656778

\section{General rights}

Copyright and moral rights for the publications made accessible in the public portal are retained by the authors and/or other copyright owners and it is a condition of accessing publications that users recognise and abide by the legal requirements associated with these rights.

- Users may download and print one copy of any publication from the public portal for the purpose of private study or research.

- You may not further distribute the material or use it for any profit-making activity or commercial gain

- You may freely distribute the URL identifying the publication in the public portal 


\title{
A Pole Pair Segment of a 2 MW High Temperature Superconducting Wind Turbine Generator
}

\author{
Xiaowei Song, Nenad Mijatovic, Member, IEEE, \\ Jürgen Kellers, Carsten Bührer, Anders V. Rebsdorf, Jesper Hansen, Mogens Christensen, Jens Krause, Hen- \\ drik Pütz, Jan Wiezoreck, and Joachim Holbøll, Senior Member, IEEE
}

\begin{abstract}
A 2 MW high temperature superconducting (HTS) generator with 24 pole pairs has been designed for the wind turbine application. In order to identify potential challenges and obtain practical knowledge prior to production, a fullsize stationary experimental set-up, which is one pole pair segment of the full generator, has been built and tested. The experimental set-up comprises a consequent-pole HTS rotor and a conventional three-phase copper stator. This paper first presents the electromagnetic designs of the full generator and the set-up, then it goes to compare the performance of the full generator and the set-up in terms of the flux density, the operating condition of the HTS winding, and the force-generation capability. Finite element (FE) software MagNet is used to carry out numerical simulations. The findings show that the HTS winding in the set-up is a good surrogate for these that would be used in the full generator. The FE simulations also tell that the maximum tangential force generated in the set-up is $3.77 \%$ lower than that in the full generator.
\end{abstract}

Good agreement between the values of interest in the set-up and those projected in the full generator has revealed a costeffective prototyping methodology for developing HTS machines.

Index Terms-Consequent-pole, electromagnetic, full-size, force, high temperature superconducting generator, wind turbine.

\section{INTRODUCTION}

$\mathbf{H}$ IGH temperature superconducting (HTS) generators are expected to be a competitive drive train for large wind turbines [1]. Advantages of HTS wind turbine generator lie in high torque densities, and consequently reduced volume and mass at the same power ratings. Compact wind turbine generators could also result in lower costs for transportation, installation, and foundation of wind turbines [2]. Therefore, study of HTS wind turbine generators has been of great interest and several designs have been proposed [3], [4].

The commercialization of HTS wind turbine generators needs demonstrations of the key technologies associated, e.g., fabrication and operation of HTS windings, validation of cryogenic systems, robustness of torque transfer elements, fault ride-through capabilities. Since reliability and costs of wind turbine drive trains have direct impact to the cost of energy (CoE), first-hand experience from projects like Suprapower,

X. Song, N. Mijatovic, and J. Holbøll are with the Center for Electric Power and Energy, Department of Electrical Engineering, Technical University of Denmark (DTU), 2800 Lyngby, Denmark (e-mail: song@elektro.dtu.dk).

J. Kellers, C. Bührer, J. Krause, H. Pütz and J. Wiezoreck are with ECO 5 GmbH, 53111 Bonn, Germany.

A. V. Rebsdorf, J. Hansen and M. Christensen are with Envision Energy Aps, 8600 Silkeborg, Denmark.

The work is supported by Innovation Fund Denmark (IFD) under the HTSGEN project.
INNWIND, EcoSwing is essential to boost confidence of HTS wind turbine generators [5]-[7].

A common way of demonstrating is building and testing downscaled prototypes. Downscaled prototypes have many benefits. For instance, the feasibility of the conceptual design could be easily validated on a downscaled prototype at a low cost. [8] presented a cryogen-free HTS generator prototype that has two iron-cored HTS windings and rotates at 10$30 \mathrm{rpm}$. [9] reported the design and testing of a $2.5 \mathrm{~kW}$ generator prototype that has an HTS stator. The experience of these downscaled prototypes is valuable because they provide an insight into the design challenges of HTS generators. However, in many cases, engineering challenges could not be revealed by the downscaled approach.

An alternative way of obtaining practical experience is to construct a portion of a full-size generator. A pole pair segment is a good choice since it represents the smallest independent electromagnetic unit in a multi-pole generator. On one hand, lessons learned in the process, e.g. the fabrication and operation of a full-size HTS winding, a cryogenic system and its sub-systems, a functional protection system, could be directly implemented in future mass production. On the other hand, the cost is comparable to that in the downscaled approach since only a portion of a full generator is invested. In addition, proper sub-suppliers for key components could be identified and developed. The main drawback is the absence of the rotation and the time-varying nature of the magnetic fields, as well as the power losses accompanying that nature.

Recognizing the benefits of the latter approach aforementioned, the HTS-GEN project was initiated in Denmark, starting in 2013. A full-size stationary experimental set-up, which is one pole pair segment of a 2 MW HTS generator with 24 pole pairs, has been built and tested. The investigation of the set-up could identify potential challenges before mass production of the full generator. The set-up comprises a consequent-pole HTS rotor and a conventional three-phase copper stator. The consequent-pole rotor is chosen for its potential to reduce the cost of the HTS winding. Each phase of the stator is fed by direct current (DC) to investigate the force-generation capability of the set-up as there is no relative rotation between the rotor and the stator. The electromagnetic designs of the full generator and the set-up are presented in the paper. Based on finite element (FE) simulations in MagNet, the performance of the full generator and the set-up is compared in terms of the flux density, the operating condition of the HTS winding, and the force-generation capability. 


\section{Electromagnetic DeSign OF THE FUll GENERATOR}

The full generator has a consequent-pole rotor and a conventional three-phase stator. This section summarizes the electromagnetic design of the full generator.

\section{A. Consequent-pole Rotor}

Consequent-pole rotors have been utilized in permanent magnet electric machines because the usage of permanent magnets could be noticeably reduced [10]-[12].

In an HTS machine, a consequent-pole rotor could lower down the cost of HTS windings. Fig. 1 illustrates a comparison between a normal rotor and a consequent-pole rotor in a fourpole HTS machine. As shown in Fig. 1, the number of HTS windings in a consequent-pole rotor is halved compared to that in a normal rotor. Cost breakdown of HTS windings would reveal that a lower cost is expected in Fig. 1 (b). The cost of HTS windings generally consists of three parts: the cost for HTS tapes, the cost for auxiliaries (e.g., coil former, bolts, supporting plates.) and the labour cost. For the same amount of HTS tapes, it is understandable that manufacturing one bigger HTS winding could be advantageous than manufacturing two smaller HTS windings since the latter needs more auxiliaries and more working hours.

Note that although the number of HTS windings in Fig. 1 (b) is halved, the total magnetic motive force (MMF) in Fig. 1 (b) should be the same as that in Fig. 1 (a) to keep the magnetic flux in the machine at the same level. Hence, the amount of HTS wires needed in Fig. 1 (a) and (b) is nearly the same except a slight difference due to end turns.

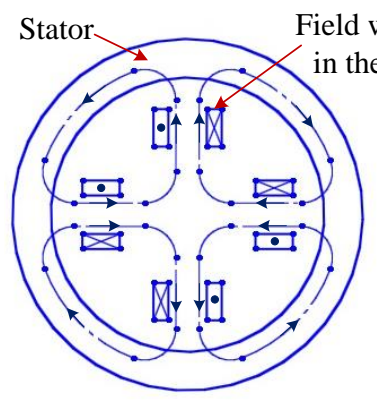

(a)

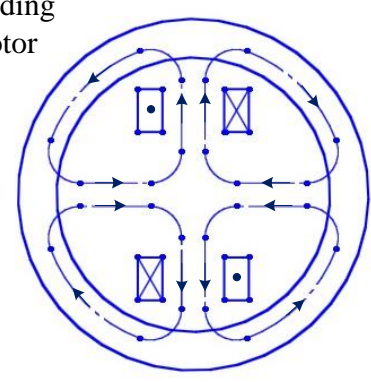

(b)
Fig. 1. Illustration of a four-pole HTS machine with a normal rotor (a) and a consequent-pole rotor (b).

\section{B. The Full Generator}

The generator employs 24 HTS windings in the rotor and a three-phase copper winding in the stator. As already explained, 24 HTS windings in a consequent-pole rotor realize a 24pole-pair machine. An imaginary configuration of the full generator and its one pole pair segment are shown in Fig. 2. Detailed generator specifications are listed in Table I, and the electromagnetic model of one pole pair section is illustrated in Fig. 3.

A cold iron pole is placed in the center of every HTS winding so that the usage of HTS tapes could be reduced. Two warm iron cores and a warm back iron are adopted in the rotor in order to guide the magnetic flux. Although the

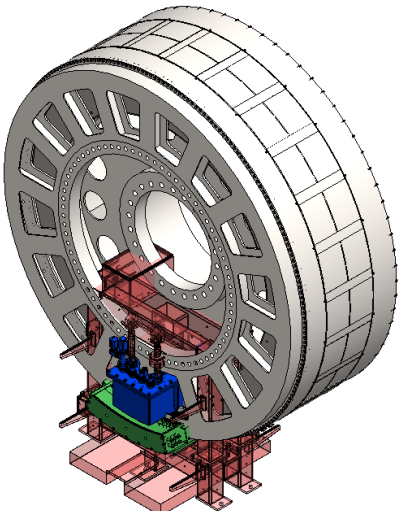

Fig. 2. Imaginary configuration of the full generator and its one pole pair segment.

TABLE I

SPECIFICATIONS OF THE FULL GENERATOR

\begin{tabular}{lc}
\hline \hline Output power (MW) & $\sim 2$ \\
Output current (A) & 162.6 \\
Rated power factor & 1 \\
Rated rotation speed (rpm) & 14.6 \\
Outer diameter of the stator yoke (mm) & 3940 \\
Inner diameter of the stator teeth (mm) & 3624 \\
Outer diameter of the rotor cryostat(mm) & 3576 \\
Inner diameter of the rotor back iron (mm) & 3330 \\
Axial length (mm) & 650 \\
Pole pair number & 24 \\
Number of slots per pole per phase & 4 \\
Operating current of the HTS winding (A) & 480 \\
Number of turns per HTS winding & 300 \\
Operating temperature of the HTS winding (K) & $\sim 30$ \\
\hline \hline
\end{tabular}

warm iron cores and the warm back iron are enclosed in the cryostat, they are not connected to the cryogenic system so that the cold mass can be reduced.

The stator is iron toothed and a laminated core is employed. Comparative studies have shown that this option offers an economical design [13]. The double-layered three-phase winding in the stator is short-pitched by one slot to reduce harmonics. In each stator slot, there is a channel between two winding layers, and the cooling oil can be injected into the slot to improve the thermal dissipation property.

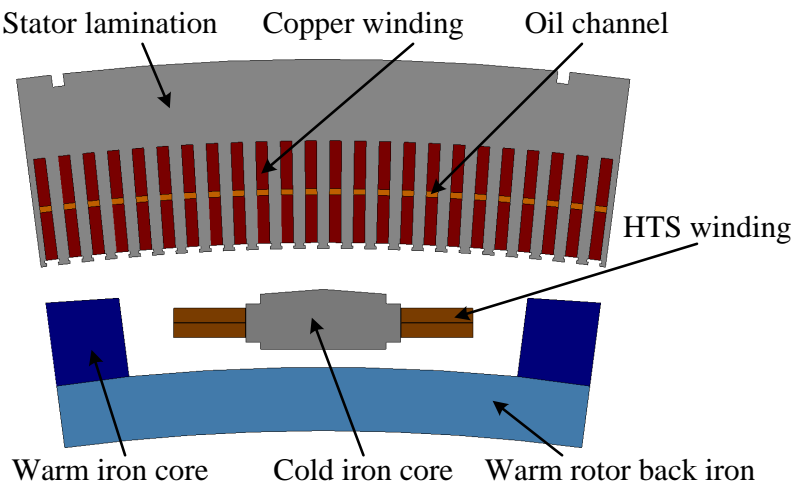

Fig. 3. Electromagnetic model of one pole pair section of the full generator. 


\section{THE EXPERIMENTAL SET-UP}

\section{A. Configuration of the Experimental Set-up}

The full-size experimental set-up constructed in the lab is shown in Fig. 4. The set-up consists of a rotor and a stator. The rotor is one pole pair section of the full generator, while the stator is wider than the rotor so that the flux generated by the HTS winding is confined to the stator. Otherwise, severe flux leakage exists. The stator is fixed to the frame and is kept stationary, and an oil circulation system is equipped to the stator, just like the case of the full generator. The rotor is mounted to the frame through swing arms, on which load cells are installed to measure the forces due to the interaction between the rotor and the stator. There are four load cells to measure the radial force, and another two load cells to measure the tangential force. The radial force provides a design reference to the supporting system of the HTS winding, whereas the tangential force can be translated to the torque and power generated by the full generator. As seen from Fig. 4, the rotor in the set-up is also stationary. Therefore, direct current (DC) is fed to each phase of the stator winding. The DC magnitude of each phase follows the value of a balanced three-phase alternating current (AC) system so that any combination of the $\mathrm{d}$-axis and q-axis currents can be investigated independently.

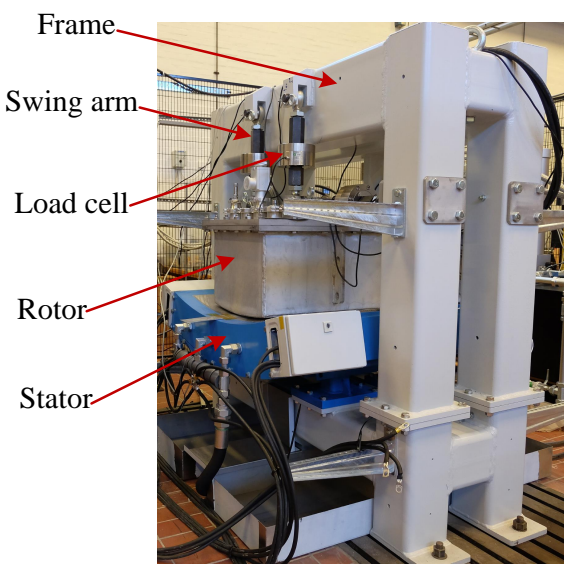

Fig. 4. The full-size experimental set-up constructed in the lab.

\section{B. Electromagnetic Model of the Experimental Set-up}

The electromagnetic model of the experimental set-up is shown in Fig. 5. Compared to Fig. 3, it is seen that the stator of the set-up is enlarged. The stator in Fig. 5 has 47 slots, which is one slot less than a two-pole-pair section of the full generator. The stator three-phase winding is distributed into 36 slots, following the same way in the full generator. The first eleven slots on both sides of the stator are half filled by glass fiber reinforced plastic (GFRP). This design ensures that the flux generated by the HTS winding could be effectively guided into the stator so that the interactive forces generated in the set-up are comparable to those in the full generator.

\section{PERFormanCE COMPARISON}

Based on FE simulations, the experimental set-up is compared to the full generator in terms of the flux density,

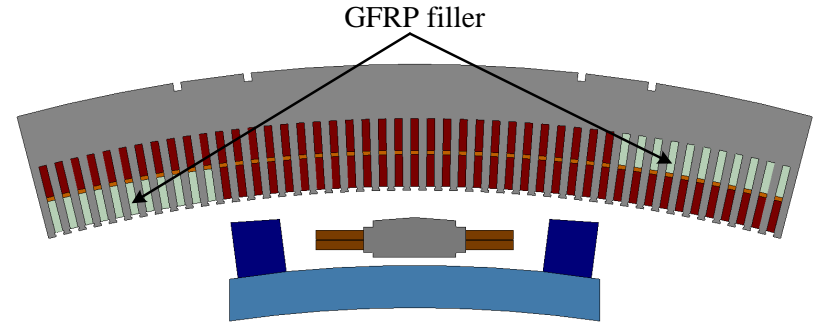

Fig. 5. Electromagnetic model of the experimental set-up.

the operating condition of the HTS winding, and the forcegeneration capability.

\section{A. Flux Density Distribution}

The flux density distribution under no load condition in the full generator and the set-up are depicted in Fig. 6 (a) and (b), respectively. The results of the FE simulations indicate that the flux densities in the full generator and the set-up have a similar contour. However, the rotor back iron and the cold iron core in the set-up are more saturated than those in the full generator, whereas the warm iron cores in the set-up are less saturated than those in the full generator. It is the neighbouring poles in the full generator that cause different saturation levels, which is also why the radial flux density at the stator inner radius of the set-up is higher, as shown in Fig. 7. Despite slightly different field levels at the stator inner radius, the slotting effect in the full generator is well reflected by the set-up.

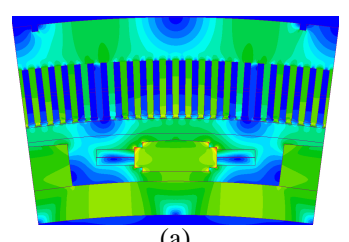

(a)

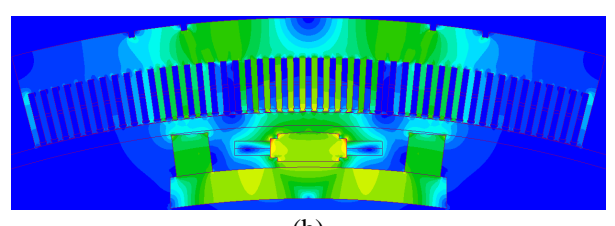

(b)

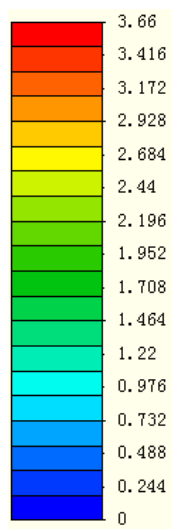

Fig. 6. The flux density distribution under no load condition in the full generator (a) and the experimental set-up (b).

\section{B. Operating Condition of the HTS Winding}

Fig. 8 presents the flux density distribution of the HTS windings in the full generator and the set-up. Both no load condition and maximum tangential force condition are computed. Under no load condition the field distribution is symmetrical, while under maximum tangential force condition the right side of the HTS winding experience higher field. So only the right side of the HTS winding is plotted. It is found that the HTS windings in the full generator and the set-up experience nearly the same magnetic field. Detailed operating condition of the HTS winding can be further revealed by the computation of the critical current. 


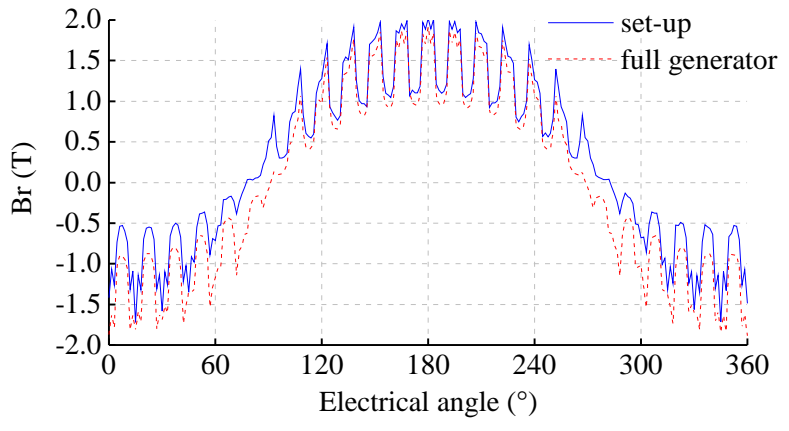

Fig. 7. The radial flux density at the stator inner radius. Similar slotting effect exists in the full generator and the set-up.

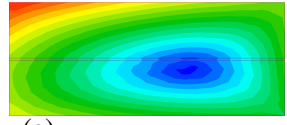

(a)

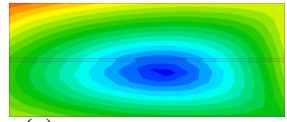

(c)

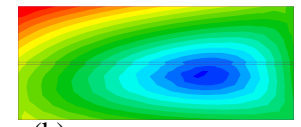

(b)

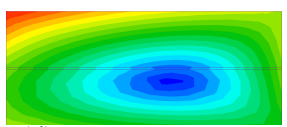

(d)

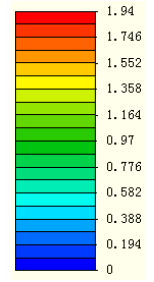

Fig. 9. Load lines of the HTS windings.
Fig. 8. The flux density distribution on the right side of the HTS winding (a): HTS winding in the set-up under no load condition; (b): HTS winding in the set-up under maximum tangential force condition; (c): HTS winding in the full generator under no load condition; (d): HTS winding in the full generator under maximum tangential force condition.

The critical current of the HTS tape depends on the field and also the angle between the field and the HTS tape [14]. To simplify the problem, the resultant field is used to assess the critical current. This gives a conservative estimation since the resultant field is always larger than the real limiting field. The load lines of the HTS winding are plotted in Fig. 9. Due to higher field level in the set-up, the load line of the HTS winding in the set-up is placed on the right.

Theoretically, the critical current is found at the field that corresponds to the operating current. Referring to the critical line provided by the HTS wire manufacture, the computed theoretical critical currents (noted as $I_{\mathrm{c} \__{-}}$) of the HTS windings in the full generator and the set-up are $680 \mathrm{~A}$ and $652 \mathrm{~A}$, respectively.

From the practical operation point of view, it is more intuitive to define the practical critical current (noted as $I_{\mathrm{c}_{-} \mathrm{p}}$ ), which is the intersection between the load line and the critical line. Unlike the theoretical critical current, the practical critical current is independent of the operating current (noted as $I_{\mathrm{op}}$ ), and it clearly limits the maximum value of $I_{\mathrm{op}}$. As read from Fig. 9, the computed $I_{\mathrm{c} \_\mathrm{p}}$ values of the HTS windings in the full generator and the set-up are $606 \mathrm{~A}$ and $592 \mathrm{~A}$, respectively.

Very close critical currents indicate that the HTS winding in the set-up is a good surrogate for these that would be used in the full generator.

\section{Forces}

The forces generated in the set-up are compared to these in one pole pair of the full generator. The tangential force is proportional to the electromagnetic torque whereas the radial force provides a reference to design a robust supporting

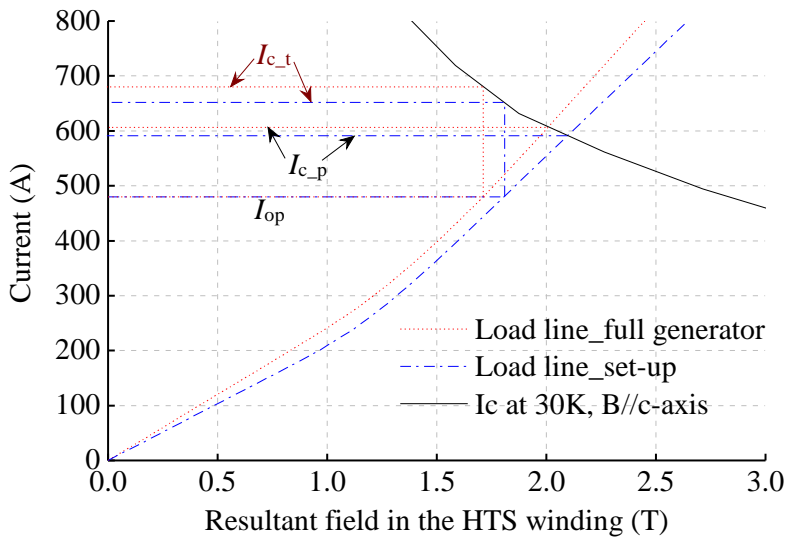

system. As seen from Fig. 10, the forces in the set-up and in the full generator follow the same profile. The maximum tangential force in the set-up is $3.77 \%$ lower than that in one pole pair of the full generator, while the maximum radial force in the set-up is $2 \%$ lower than that in one pole pair of the full generator. The deviation could due to the effects of neighbouring poles in the full generator. Hence, the torquegeneration capability as well as the strength requirements of the supporting system in the full generator can be well predicted in the set-up.

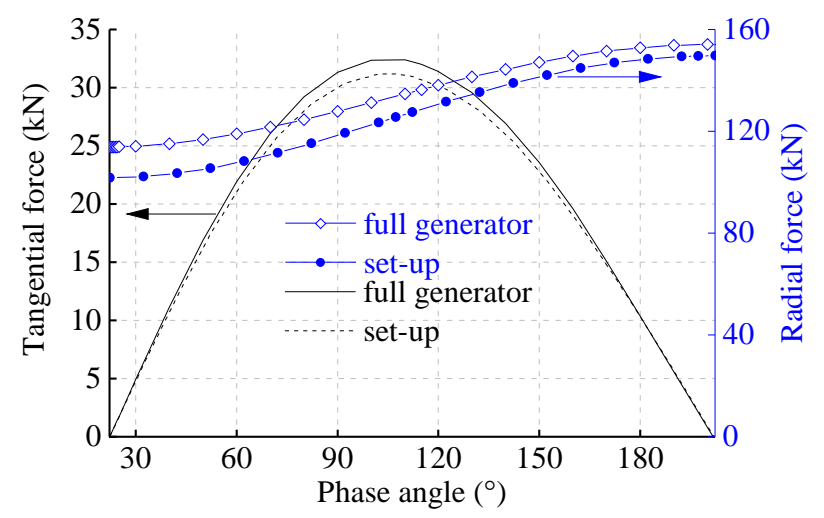

Fig. 10. The forces generated in the set-up and in one pole pair of the full generator with respect to the phase angle in phase A of the stator.

\section{CONCLUSION}

Before investing a 2 MW HTS wind turbine generator, a full-size stationary experimental set-up is designed and being tested to validate the generator design and tackle potential challenges. The set-up is based on one pole pair section of the full generator, and appropriate modifications are made to duplicate the performance of the full generator to the utmost. The FE simulations are carried out to compare the performance of the set-up and the full generator in terms of the flux density, the operating condition of the HTS winding, and the force-generation capability. The findings prove that the setup being studied could factually reveal the performance of the full generator. The deviation could due to the effects of neighbouring poles in the full generator. The testing on the set-up will be reported later on. 


\section{REFERENCES}

[1] B. B. Jensen, N. Mijatovic, and A. B. Abrahamsen, "Development of superconducting wind turbine generators," J. Renew. Sustain. Energy, vol. 5, no. 2, Mar. 2013, Art. No. 023137.

[2] G. Snitchler, B. Gamble, C. King, and P. Winn, "10 MW class superconductor wind turbine generators," IEEE Trans. Appl. Supercond., vol. 21, no. 3, pp. 1089-1092, Jun. 2011.

[3] A. B. Abrahamsen, N. Mijatovic, E. Seiler, T. Zirngibl, C. Træholt, P. B. Nørgård, N. F. Pedersen, N. H. Andersen, and J. Østergaard, "Superconducting wind turbine generators," Supercond. Sci. Technol., vol. 23, no. 3, 2010, Art. No. 034019.

[4] Y. Terao, M. Sekino, and H. Ohsaki, "Comparison of conventional and superconducting generator concepts for offshore wind turbines," IEEE Trans. Appl. Supercond., vol. 23, no. 3, Jun. 2013, Art. No. 5200904.

[5] [Online].Available:http://www.suprapower-fp7.eu.

[6] [Online].Available:http://www.innwind.eu.

[7] [Online].Available:http://www.ecoswing.eu.

[8] Y. Yang, S. Duan, Y. Ren, Y. Jiang, L. Feng, X. Zhang, H. Chai, M. Kuang, J. Wu, X. Yang et al., "Design and development of a cryogenfree superconducting prototype generator with YBCO field windings," IEEE Trans. Appl. Supercond., vol. 26, no. 4, Jun. 2016, Art. No. 5200205.

[9] T. Qu, P. Song, X. Yu, C. Gu, L. Li, X. Li, D. Wang, B. Hu, D. Chen, P. Zeng et al., "Development and testing of a $2.5 \mathrm{~kW}$ synchronous generator with a high temperature superconducting stator and permanent magnet rotor," Supercond. Sci. Technol., vol. 27, no. 4, 2014, Art. No. 044026.

[10] J. A. Tapia, F. Leonardi, and T. A. Lipo, "Consequent-pole permanentmagnet machine with extended field-weakening capability," IEEE Transactions on Ind. Appl., vol. 39, no. 6, pp. 1704-1709, Nov./Dec. 2003.

[11] J. Amemiya, A. Chiba, D. G. Dorrell, and T. Fukao, "Basic characteristics of a consequent-pole-type bearingless motor," IEEE Trans. Magn., vol. 41, no. 1, pp. 82-89, Jan. 2005.

[12] Y. Gao, R. Qu, D. Li, J. Li, and G. Zhou, "Consequent-pole flux-reversal permanent-magnet machine for electric vehicle propulsion," IEEE Trans. Appl. Supercond., vol. 26, no. 4, Jun. 2016, Art. No. 5200105.

[13] H. Karmaker, M. Ho, and D. Kulkarni, "Comparison between different design topologies for multi-megawatt direct drive wind generators using improved second generation high temperature superconductors," IEEE Trans. Appl. Supercond., vol. 25, no. 3, Jun. 2015, Art. No. 5201605.

[14] V. Lombardo, E. Barzi, G. Norcia, M. Lamm, D. Turrioni, T. Van Raes, and A. Zlobin, "Study of HTS insert coils for high field solenoids," in AIP Conf. Proc., vol. 1218, no. Fermilab-pub-09-454-TD, 2009, pp. 246-253. 